\title{
Zeolite ZSM-5 Membranes Grown on Porous $\alpha-\mathrm{Al}_{2} \mathrm{O}_{3}$
}

\author{
Yushan Yan, Michael Tsapatsis, George R. Gavalas and Mark E. Davis* \\ Chemical Engineering, California Institute of Technology, Pasadena, CA 91125, USA
}

ZSM-5 membranes with good permeation selectivity for $n$-butane-isobutane are grown hydrothermally from a clear solution on horizontally-held porous $\alpha-\mathrm{Al}_{2} \mathrm{O}_{3}$ disks.

Zeolites have found widespread applications as catalysts and separation media. At present, all technologies exploiting these materials use the zeolite in powder composite form. The desire to translate the molkcular sieving properties of zeolite powder composites into a membrane configuration has long been recognized. To prepare such a membrane, the crystals must grow in an interlocking fashion to form a continuous layer on a porous substrate so that the only available transport pathways are through the zeolite pores. This layer must be mechanically durable but thin to provide good flux. Over the past two years great progress has been achieved towards this goal. Most reported membranes were silicalite or ZSM-51-5 [membrane growth on macroporous steel wool, ${ }^{1,2}$ mesoporous ( $\left.\mathrm{ca} .5 \mathrm{~nm}\right) \gamma$ $\mathrm{Al}_{2} \mathrm{O}_{3}, 3,4$ and macroporous $\alpha-\mathrm{Al}_{2} \mathrm{O}_{3}{ }^{5}$ supports], but a ferrierite membrane has also been reported ${ }^{6}$ (growth on macroporous $\alpha$ $\mathrm{Al}_{2} \mathrm{O}_{3}$ ). In all cases, the syntheses were accomplished by contacting the support with a synthesis gel, but composition and location or orientation of the support varied among the different preparations. The membranes were tested in permeation of pure gases, separation of gas mixtures, or separation of liquid mixtures. The pure gas permeation ratio of $n$-butane to isobutane was sometimes used as a yardstick of membrane quality because the kinetic diameters of these two gases are approximately 4.3 and $5 \AA$, respectively, compared to the approximately $5.5 \AA^{7}$ pore size of ZSM-5. Some of the membranes prepared had $n$-butane: isobutane ratios as high as 60 at room temperature but declined to 1 at $200^{\circ} \mathrm{C} .1,2$

The present study differs from the previous ones ${ }^{1-6}$ in the use of a clear synthesis solution rather than a gel and in the locationorientation of the support during the synthesis. Perhaps these differences are responsible for the observed different dependence of gas fluxes with temperature and particularly the increase rather than decrease of the $n$-butane : isobutane flux ratio with increasing temperature.

Our synthesis employed porous disks of $99.8 \% \alpha-\mathrm{Al}_{2} \mathrm{O}_{3}$ (Coors Ceramic Company, $5 \mathrm{~cm}$ diameter, $0.6 \mathrm{~cm}$ thickness, 0.5 $\mu \mathrm{m}$ pore size) fixed horizontally in a PTFE holder that was positioned just below the surface of a clear liquid of composition TPAOH $-4 \mathrm{NaOH}-0.005 \mathrm{Al}_{2} \mathrm{O}_{3}-6 \mathrm{SiO}_{2}-571 \mathrm{H}_{2} \mathrm{O}$ (TPAOH $=$ tetrapropylammonium hydroxide). The reaction system was enclosed in a PTFE v essel, placed into a stainless steel autoclave and heated at $175^{\circ} \mathrm{C}$ for $16 \mathrm{~h}$ at autogenous pressure. The ZSM5 film grew on the bottom face of the $\alpha-\mathrm{Al}_{2} \mathrm{O}_{3}$ disk. Numerous synthetic variations were attempted and it appears that the placement of the disk and the liquid composition are important for the synthesis of good films. At this time we are continuing to explore the relationships between the preparation procedure and the resulting membrane fluxes. Therefore, we present here both our best results and the range of values that we have observed over several membranes (see Table 1). Upon removal of the zeolite-alumina composite membrane from the synthesis vessel, the material was washed with water and dried at $110^{\circ} \mathrm{C}$ in air. The membrane was then calcined at $500^{\circ} \mathrm{C}$ in air for $13 \mathrm{~h}$ to remove the TPA occluded within the ZSM-5 (existence of ZSM-5 verified by X-ray diffraction measurements). Fig. 1 shows scanning electron micrographs from a representative ZSM-5- $\alpha-\mathrm{Al}_{2} \mathrm{O}_{3}$ composite membrane. The zeolite membrane is approximately $10 \mu \mathrm{m}$ thick and consists of a continuous layer of highly intergorwn crystals of ZSM-5.

Permeation measurements on the ZSM-5 membranes were conducted at temperatures below $473 \mathrm{~K}$ because the disks were attached to the measurement apparatus by epoxy cement. Higher temperatures will be investigated at a later date. Pure gas permeation measurements were run by passing feed gas at 1.27 atm on one side of the membrane and beginning with a vacuum on the other side. Fluxes were determined by measuring the pressure increase on the evacuated side of the membrane. Repeat measurements were always performed and the flux of $\mathrm{H}_{2}$ was recorded after each measurement with all other species to ensure that no residual material, e.g. hydrocarbon, remained adsorbed in the zeolite. At all times, the $\mathrm{H}_{2}$ flux returned to the reported value. Table 1 shows the permeation data obtained from the zeolite-alumina composite membranes for several gases at temperatures below $473 \mathrm{~K}$. First, it can be seen that the membrane fluxes are dramatically reduced from those of the bare $\alpha-\mathrm{Al}_{2} \mathrm{O}_{3}$ substrate as expected. Second, the flux ratios vary dramatically when comparing the $\alpha-\mathrm{Al}_{2} \mathrm{O}_{3}$ to the zeolite membrane, e.g. $n$-butane-isobutane at $303 \mathrm{~K}: 18$ (membrane) vs. $0.9\left(\alpha-\mathrm{Al}_{2} \mathrm{O}_{3}\right)$. Third, at $458 \mathrm{~K}$, the flux ratio $n$-butaneisobutane is 31 and this is the highest value reported at temperatures above ambient for a zeolite membrane of any kind. The data shown in Table 1 strongly suggest that the molecular transport occurs only via the zeolitic pores, i.e. large differences between molecules that are nearly the size of the pore ( $n$-butane $v s$. isobutane) and essentially no variation amongst molecules of similar molecular weight and of size well below that of the

Table 1 Pure gas permeation measurements

\begin{tabular}{|c|c|c|c|c|c|c|c|}
\hline & \multicolumn{7}{|c|}{ Gas flux $\times 10^{2} /\left[\left(\mathrm{cm}^{3} \mathrm{STP}\right) /\left(\mathrm{cm}^{2} \min\right.\right.$ atm $\left.)\right]$} \\
\hline & $\mathrm{H}_{2}$ & $\mathrm{He}$ & $\mathrm{N}_{2}$ & $\mathrm{O}_{2}$ & $\mathrm{CH}_{4}$ & $n$-butane & isobutane \\
\hline \multirow{5}{*}{ 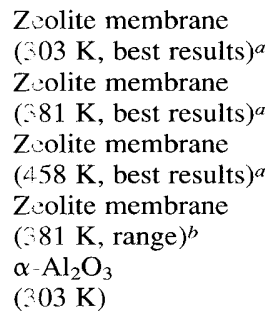 } & 84.0 & 40.8 & 43.0 & 50.0 & 50.6 & 10.2 & 0.6 \\
\hline & 122.4 & 58.8 & 65.1 & 61.2 & 107.3 & 46.1 & 1.6 \\
\hline & 137.6 & 67.5 & 54.5 & 55.7 & 99.7 & 79.4 & 2.6 \\
\hline & $122.4-25.2$ & - & $65.1-14.8$ & $61.2-13.2$ & - & $46.1-15.1$ & $2.41-1.6$ \\
\hline & 4459 & 2769 & 1460 & 1293 & 2098 & 1916 & 2063 \\
\hline
\end{tabular}

\footnotetext{
${ }^{a}$ Obtained from the same membrane. ${ }^{b}$ Range observed from three different membranes. ${ }^{c}$ Standard temperature and pressure.
} 

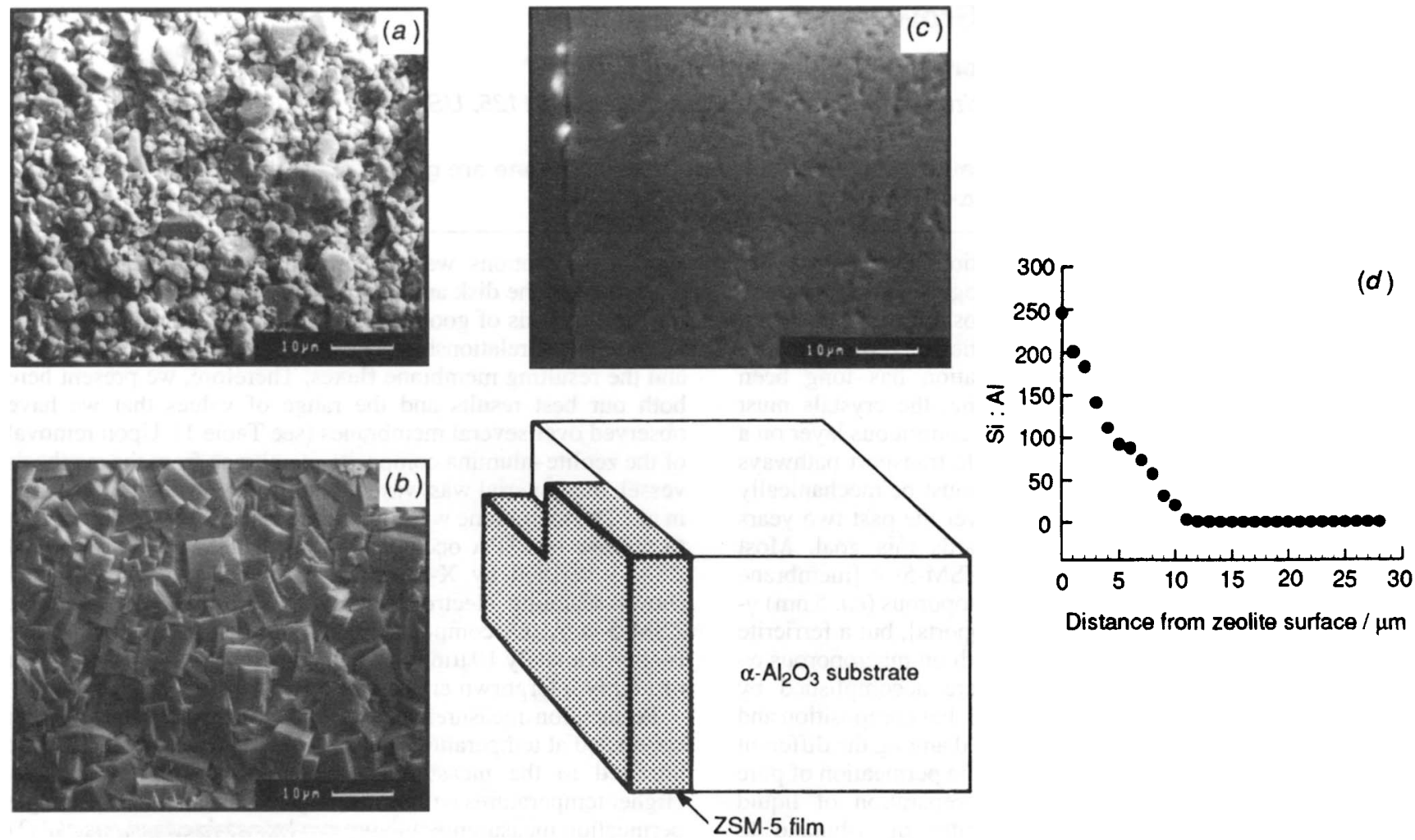

Fig. 1 Scanning electron micrographs $(a, b, c)$ and results of electron microprobe analysis $(d)$. (a) Top view of bare alumina substrate; (b) top view of composite membrane; (c) cross-sectional view of composite membrane; (d) Si : Al ratio of composite membrane cross-section.

ZSM-5 pore diameter $\left(\mathrm{N}_{2}\right.$ vs. $\mathrm{O}_{2}$, kinetic diameters of 3.64 and $3.46 \AA$, respectively). ${ }^{8}$

The most sensitive test for whether the molecular transport is through the zeolite pores alone is to use a probe molecule too large to enter the zeolite pores. Here, we used trisopropylbenzene (TIPB) as the probe molecule since it is known that it cannot enter the pores of ZSM-5 at temperatures below 473 K. ${ }^{9}$ TIPB was vaporized in a flowing stream of $\mathrm{N}_{2}$. Since $\mathrm{N}_{2}$ can pass through the membrane, the measurement of flux by pressure increase as used in the pure gas experiments was not possible, so the molecules passing through the membrane were collected and analysed by gas chromatography. The detection limit of the apparatus is $10^{-7} \mathrm{~cm}^{3}$ (STP)/(cm-2 $\mathrm{min}$ ) for TIPB. With a porous Vycor glass tube ( $40 \AA$ pores), TIPB was clearly observed to transport through the tube wall. At temperatures as high as $458 \mathrm{~K}$, no TIPB was detected from all of the ZSM-5- $\alpha$ $\mathrm{Al}_{2} \mathrm{O}_{3}$ membranes we have synthesized. These data and those shown in Table 1 are very strong indications that the zeolite membranes are essentially defect-free.

Several reports of polycrystalline ZSM-5 films have appeared. However, these films reveal different permeation properties to those shown here, especially with respect to the temperature dependence. Clearly, our method of preparation is significantly different from all others published and we are currently investigating the parameters that are necessary for achieving higher gas fluxes.
This work was supported by the US National Science Foundation.

Received, 16th November 1994; Com. 4/07004F

\section{References}

1 E. R. Geus, H. van Bekkum, W. J. W. Bakker and J. A. Mouljin, Microporous Mater., 1993, 1, 131.

2 W. J. W. Bakker, G. Zheng, F. Kapteijn, M. Makhee, J. A. Mouljin, E. R. Geus and H. van Bekkum, Precision Process Technology, ed. M. P. C. Weijnen and A. A. H. Drinkenburg, Kluwer, Amsterdam, 1993 , p. 425.

3 M. D. Jia, K. V. Peinemann and R. D. Behling, J. Membr. Sci., 1993, $82,15$.

4 M. D. Jia, B. Chen, R. D. Noble and J. L. Falconer, J. Membr. Sci., 1994, 90, 1.

5 T. Sano, M. Hasegawa, Y. Kawakami, Y. Kiyozumi, H. Yanagishita, D. Kitamoto and F. Mizukami, Stud. Sur. Sci. Catal., 1994, 84, 1175 .

6 M. Matsukata, N. Nishiyama and K. Ueyama, Stud. Sur. Sci. Catal., 1994, 84, 1183.

7 W. M. Meier and D. H. Olson, Atlas of Zeolitic Structure Types, Butterworths, London, 1987.

8 D. W. Breck, Zeolite Molecular Sieves, Wiley, New York, 1974

9 M. H. Kim, C. Y. Chen and M. E. Davis, ACS Symp. Ser., 1993, 517, 222. 